$\mathbb{T}$ periodica polytechnica

Civil Engineering

$52 / 1(2008) 45+53$

doi: 10.3311/pp.ci.2008-1.07

web: http://www.pp.bme.hu/ci

(c) Periodica Polytechnica 2008

RESEARCH ARTICLE

\section{Influence of temperature distribution on the design of pavement structures}

László Pethő

Received 2007-12-05

\begin{abstract}
The bearing capacity of asphalt pavement structures is not constant due to the continuous change of temperature, and the importance of temperature change varies layer by layer. In the present article we reveal to what extent temperature change influences cumulated fatigue with the application of detailed pavement structure models and which seasons and parts of the day are significant in terms of fatigue. The pavement structure models were set up on the basis of stiffness tests performed in laboratory and on the data supplied by a temperature detector placed into a pavement structure. The set of data contains the results of measurements of one year with the measurement frequency of 10 minutes.
\end{abstract}

\section{Keywords}

fatigue cracking $\cdot$ bearing capacity $\cdot$ environment

\section{László Pethő}

Department of Highway and Railway Engineering, BME, Múegyetem rkp. 3. Budapest, H-1521, Hungary

e-mail: petho@uvt.bme.hu

\section{Introduction}

The fact that the material performance of the pavement layers depends highly on temperature is a very important feature of asphalt pavements. The temperature of the various layers and parallel to that the characteristics of their material change continuously in time, what makes the modelling and design even more difficult. In the following study fatigue design of asphalt pavements (an important part of the design procedure) will be analysed in terms of temperature changes. The importance of the temperature dependent definition of material features will be presented and an analysis will be provided on what temperature values and in accordance with then what periods can be definitive in terms of fatigue. The study will not deal with the design of subbase and subgrade; their characteristics will be considered constant in terms of time.

\section{Modelling}

Detailed asphalt pavement models were established based on stiffness test performed on four mix types on broad temperature scale and on data obtained from a temperature detector placed in a pavement structure in traffic.

During modelling the temperature can be specified at a given depth in any moment on one hand, and the stiffness of the given mix can be defined as the function of this temperature on the other. In our calculation full depth asphalt pavement as well as asphalt pavement on $150 \mathrm{~mm}$ thick lean concrete subbase were taken into consideration in traffic loading class $\mathrm{C}, \mathrm{D}, \mathrm{E}$ and $\mathrm{K}$ (Table 1) applying three layer structure types (Table 2).

The type of pavement structure and the structure according to traffic load category was defined as the result of applying four different asphalt mixes.

During the establishment of models used for detailed calculations the following main aspects were taken into account:

- The surface modulus of the subgrade was $40 \mathrm{MPa}$ in every case.

- Full friction was taken into consideration between the asphalt layers in every case [10] partial slip was assumed between the other layers $(\mathrm{RSC}=1.5 \mathrm{~m})$. 
Tab. 1. Pavement thickness according to the load classes

Tab. 2. Pavement structure types for modelling

\begin{tabular}{cccccc}
\hline \multicolumn{2}{c}{ load class } & C & D & E & K \\
\hline \multicolumn{2}{c}{ number of load repetition (Mio, ESAL) } & $0.3-1.0$ & $1.0-3.0$ & $3.0-10.0$ & $10.0-30.0$ \\
\hline $\begin{array}{c}\text { full depth asphalt } \\
\text { pavement structure }\end{array}$ & asphalt thickness (cm) & 18 & 21 & 24 & 27 \\
\hline $\begin{array}{c}\text { asphalt pavement structure } \\
\text { on hydraulically bonded } \\
\text { subbase }\end{array}$ & asphalt thickness (cm) & 13 & 17 & 20 & 24 \\
\hline
\end{tabular}

\begin{tabular}{cccc}
\hline type & I & II & III \\
\hline wearing course & AC 11 (AB-11/F) & AC 11 (AB-11/F) & SMA-11 (mZMA-11) \\
base course & AC-22 (K22/F) & AC-22, HMA (mK22/NM) & AC-22, HMA (mK22/NM) \\
base course & AC-22 (K22/F) & AC-22 (K22/F) & AC-22 (K22/F) \\
\hline
\end{tabular}

searching the correlation of regression between temperature values measured in 10 minutes and depth

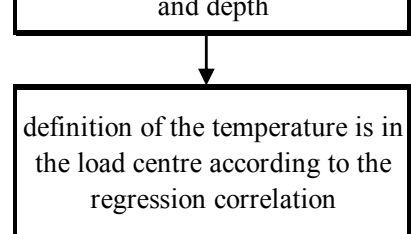

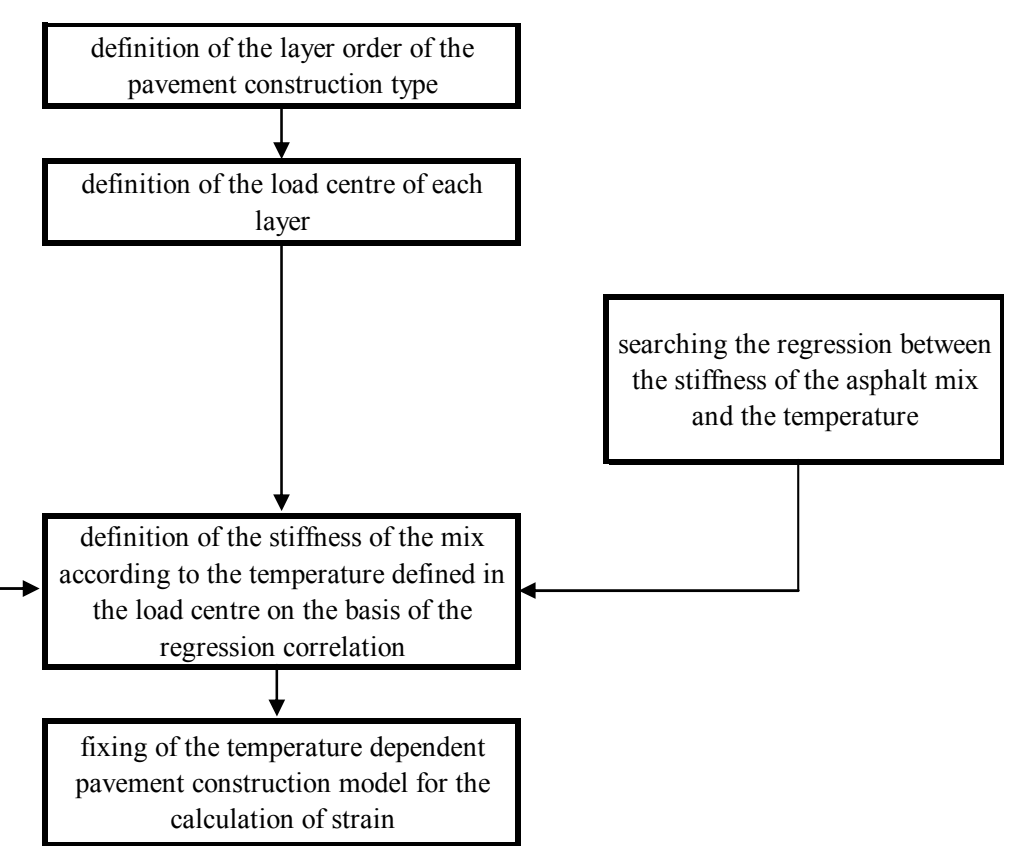

Fig. 1. Detailed asphalt pavement structure models 
- The stiffness of layer hydraulically bonded subbase was always defined at the value of $5000 \mathrm{MPa}[10]$;

- The Poisson factor of every layer was considered at the value of 0.35 [3];

- The value of the loading force during the calculation of stress was $F=50 \mathrm{kN}$, which is distributed evenly on a circular plate with the radius of $r=0.1575$, and has no horizontal component.

\subsection{Layer characteristics, mix characteristics}

The dynamic modulus was defined according to MSZ EN 12697-26. The dependence on temperature and loading frequency of the stiffness of asphalt mixes have already been revealed by national and international tests.

Four asphalt mix types were used in the test, those were sampled from construction sites. The values of stiffness in the function of temperature were defined with the help of regression correlations. In the range between $-20^{\circ} \mathrm{C}$ and $+10^{\circ} \mathrm{C}$ straight-line alignment can be applied, in the range between $+10^{\circ} \mathrm{C}-+55^{\circ} \mathrm{C}$ third degree polynomial can be used for approaching the correlation between stiffness and temperature adequately. Since the correlation coefficient $\mathrm{R}^{2}$ is always higher than 0.99 , the applicability of correlation described as functional relationship can be considered as proven. The functions are summarized in Table 3

It is an important fact that the mix can be represented by its stiffness measured and interpreted on equivalent temperature to certain extent, however the change of stiffness according to the temperature influences the pavement structure design.

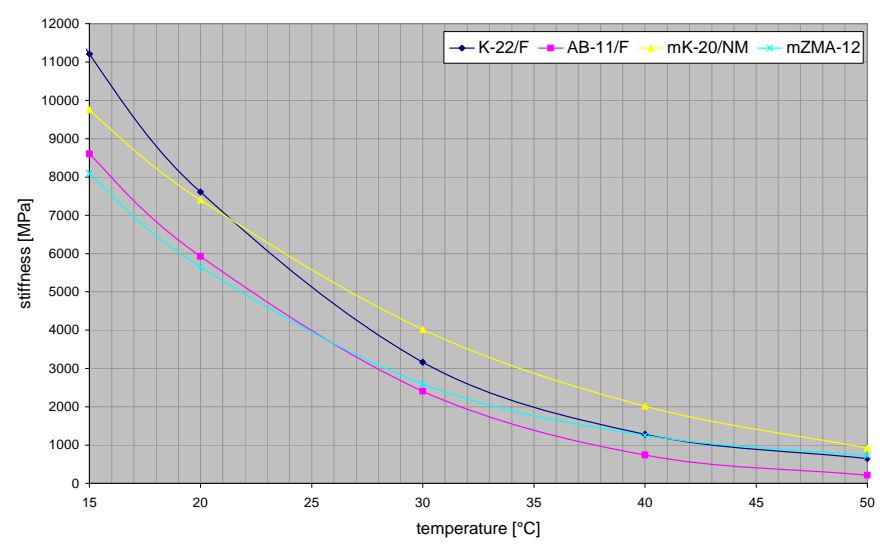

Fig. 2. Variation of the stiffness of the applied asphalt mixtures in the function of temperature

\subsection{Temperature of the pavement structure}

The vertical temperature distribution of the pavement structure essentially depends on weather conditions, the thermophysical features of the subbase and subgrade as well as the pavement structure layers [1]. The individual effects of the factors influencing temperature are not considered, only the actual temperature distribution provided by the complex effects of the various elements are taken into consideration. The asphalt mix plant of Hungarian Asphalt Ltd. had the opportunity of placing a vertical temperature detector during the full reconstruction of its internal road network.

The temperature detector is a BBS-03 type soil sampler placed in the pavement structure. The device measures the temperature starting from the surface of the pavement: at the depth of $0 \mathrm{~cm} ;-2 \mathrm{~cm} ;-7 \mathrm{~cm} ;-14 \mathrm{~cm} ;-29 \mathrm{~cm} ;-49 \mathrm{~cm}$. The internal resolution of the temperature detectors is $0.0625^{\circ} \mathrm{C}$, while the accuracy of the output is $0.1^{\circ} \mathrm{C}$. The measurement station placed in the pavement structure recorded the temperature of the pavement simultaneously with the air temperature in every $10^{\text {th }}$ minute. Thus 144 records were obtained in 24 hours and 52560 in 365 days. The measurement station sent the recorded data to me via GSM adapter as E-mail messages in MS Access database. In terms of energy supply the measurement station was implemented as an independent system.

\subsubsection{Selection of significant temperatures}

Preliminary test calculations were performed on the 52560 pavement structure in the function of stiffness. It we ascertained that on the basis of the surface modulus and the change of bending the 10 minute measurement values can be averaged for the periods between 0:00 and 04:00 as well as 22:00 and 00:00 hours without any looses of information. The same method can be applied for averaging the daytime period for every hour. Thus the 24-hour period was characterized with 20 models, i.e. with 7300 pavement structure models for 365 days.

\subsubsection{Implementation of temperature measurement results into the pavement structure models}

The temperature distribution characterized by 6 points in terms of depth determines the pavement structure well; regressive straight line could be aligned to the 6 measured values in the function of depth. The calculation of regression was completed for all the measurement results of $6 * 24 * 365=52.560$, where the values of the coefficients were defined, the values of $\mathrm{R}^{2}$ were read and stored in the database. A third degree polynomial satisfied the correlation of regression in every case, the correlation coefficient remained below $R^{2}=0.8$ in 246 cases, below $R^{2}=0.7$ in 173 cases, which amount to $0.5-0.5$ percent of the cases. The relative distribution of $R^{2}$ for all the measurements is presented in Fig. 3 .

\section{The algorithm of the definition of partial fatigue val- ues}

The stresses in the pavement structure were calculated, the temperature value interpreted in the load centre of the lowest layer of the asphalt pavement structure were calculated from the temperature measurement values, and the fatigue curve of the mix to be interpreted at the given temperature of the mix was associated with temperature value on the basis of which the allowed cycle number interpreted at a given temperature and stress could be identified. The actual cycle number derived from traffic 
Tab. 3. Equation of asphalt mixture stiffness in the function of temperature

\begin{tabular}{|c|c|c|c|}
\hline temperature range & $-20^{0} \mathrm{C}-+10^{0}$ & $+10^{0} \mathrm{C}-+55^{0} \mathrm{C}$ & \\
\hline $\operatorname{mix}$ & $\begin{array}{l}\text { equation of stiffness variation in } \\
\text { the function of temperature }\end{array}$ & $\begin{array}{l}\text { equation of stiffness variation in } \\
\text { the function of temperature }\end{array}$ & $R^{2}$ \\
\hline K22/F (base course) & $y=-695.88 x+22779$ & $y=-0.2212 \times 3+32.771 \times 2-1663.3 x+29537$ & 1.00 \\
\hline AB-11/F (wearing course) & $y=-702.56 x+18669$ & $y=0.11677 \times 3+19.743 \times 2-1117.2+21307$ & 1.00 \\
\hline mK-20/NM (base course) & $y=-700 x+19636$ & $y=-0.0785 \times 3+13.984 x+20201$ & 1.00 \\
\hline mZMA-12 (wearing course) & $y=-700 x+18311$ & $y=-0.1498 \times 3+22.031 x 2-1122.2 x+20480$ & 1.00 \\
\hline
\end{tabular}

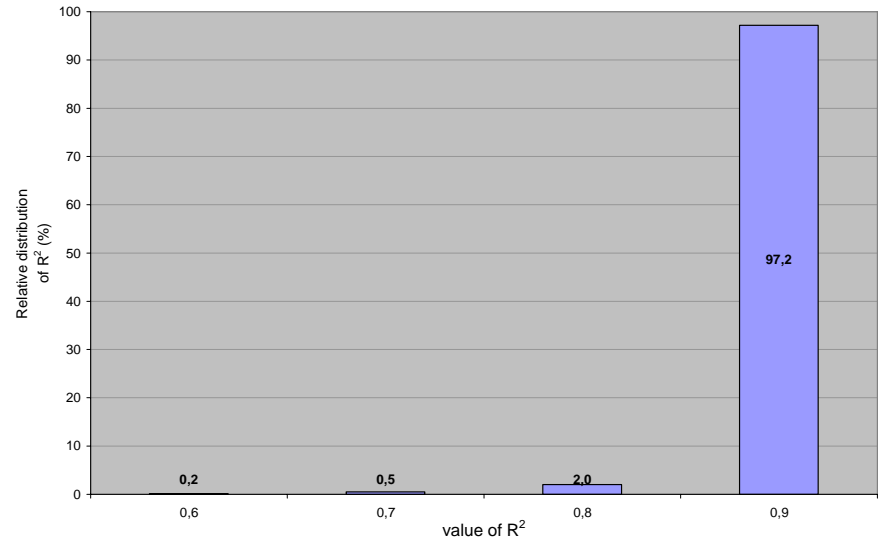

Fig. 3. Relative distribution of the values of $\mathrm{R}^{2}$

survey results and the partial fatigue values were calculated in a way that it was divided by the allowed cycle number according to the Miner-hypothesis. The cumulated fatigue projected for the period of one year can be calculated by totalling the values to 365 days. The algorithm of the procedure is presented on Fig. 4

\subsection{Method of the identification of stresses}

The horizontal strains were identified on the basis of design models with the help of SHELL - BISAR 3.0 software on the bottom of asphalt pavement structures. An individual database was created in every traffic load category and for every pavement structure type. Each database contains 7300 pavement structure models. This means the generation and calculation of $2 * 4 * 3 * 7.300=175.200$ pavement structure models. The large number of calculations was resolved by the application of an MS Windows based individual auxiliary program. The detailed pavement structure models were used to achieve better approximation of reality. Cumulative fatigue hypothesis of Miner is used widely for the description of pavement structures [8, 11, 14].

\subsection{Definition of the allowed strains in the asphalt pavement} structure

The fatigue tests in the laboratory are fundamentally different in their characters and the allowed tensile strains (and load cycle numbers) obtained as the results are applied after recalculation with various factors in accordance with the design concept. The general correlation is as follows:

$$
N=k_{1} *\left(\varepsilon_{\text {tensile }}\right)^{-k_{2}}
$$

The following correlation was worked out for the implementation of a cumulative fatigue test performed at variable temperatures, which considers the followings:

- the fatigue curve is shifted in parallel with itself in comparison with the curve interpreted at the reference temperature during temperature changes;

- the fatigue curve is shifted due to insertion of load breaks, of which the shift is also temperature dependent.

$$
N=\left(10^{\left(f_{1}+f_{2}\right)} * f_{3}\right) * \varepsilon^{f_{4}}
$$

where

$f_{1}$ is the constant exponent interpreted at reference temperature. The value of $10^{(f 1)}$ is derived from the $\mathrm{k}_{1}$ parameter of Eq. 1

$\mathrm{f}_{2}$ is a parameter expressing temperature change and changing the value of the constant exponent;

$\mathrm{f}_{3}$ is a parameter expressing load breaks (healing effect);

$\mathrm{f}_{4}$ is an exponent interpreted at reference temperature. Parameter $\mathrm{f}_{4}$ can be derived from parameter $\mathrm{k}_{2}$ of $\mathrm{Eq}$. 1

During the validation of laboratory tests and stresses generated in real pavement structures the application of a so-called shift factor is necessary, with the application of which the given fatigue curves can be shifted in parallel with themselves, thus realistic conditions can be approached more effectively. The value of the shift factor varies between 5 and 700. The differences of the various shift factors and the spectrum of the shift factors to be associated with the given curves demonstrate unambiguously that simplifications applied during the design of the pavement structure referring to load, material parameters, climatic and fatigue conditions must be corrected during validation [6, 9]. Eq. 2 does not take the transverse distribution of the wheels into consideration [2]

\subsection{Modification of the fatigue curve according to tempera- ture; sensitivity test of Shell Grand-Couronne}

Calculations were completed for twelve mixes of different composition on the basis of the correlation of FranckenVerstraeten-Veverka, during which the possible technological variations of the mix composition were taken into account. The 


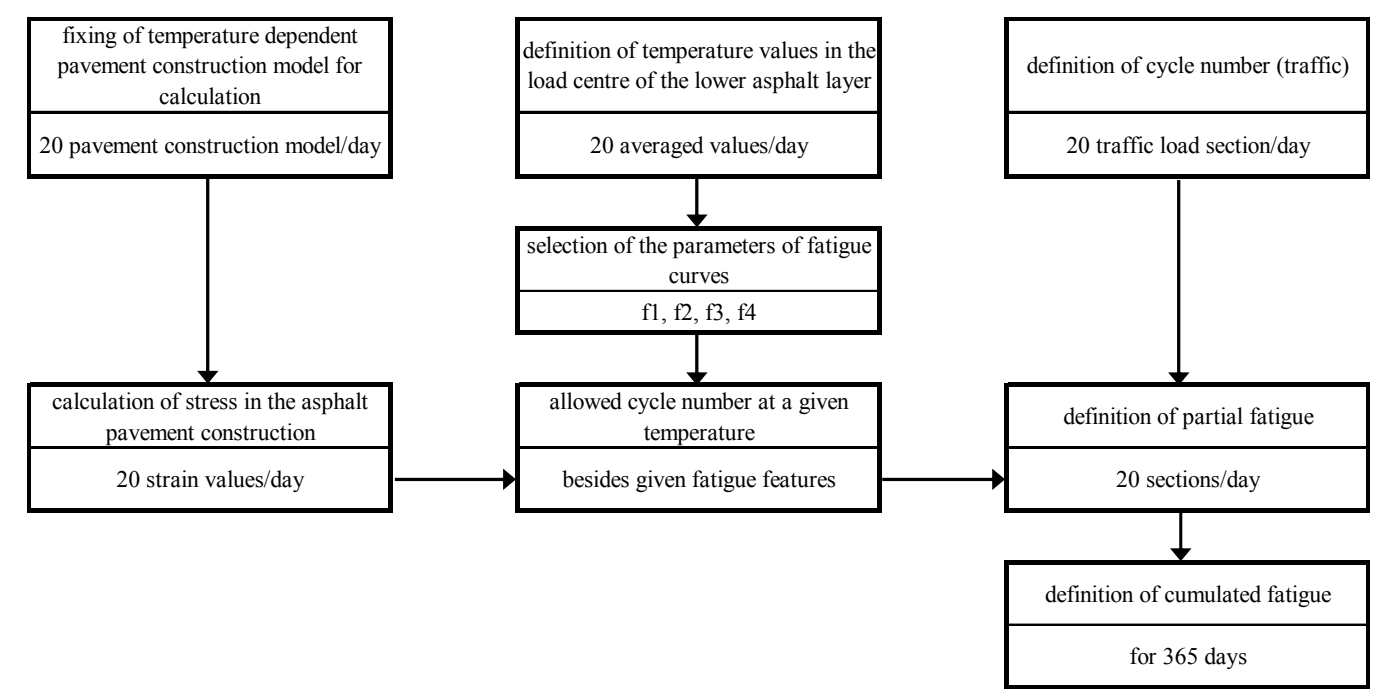

Fig. 4. Algorithm for calculating the partial fatigue values

fatigue straight-line defined in accordance with the mix and the temperature changes are showed in Fig. 5 where the equations of the two side straight lines are included for demonstration.

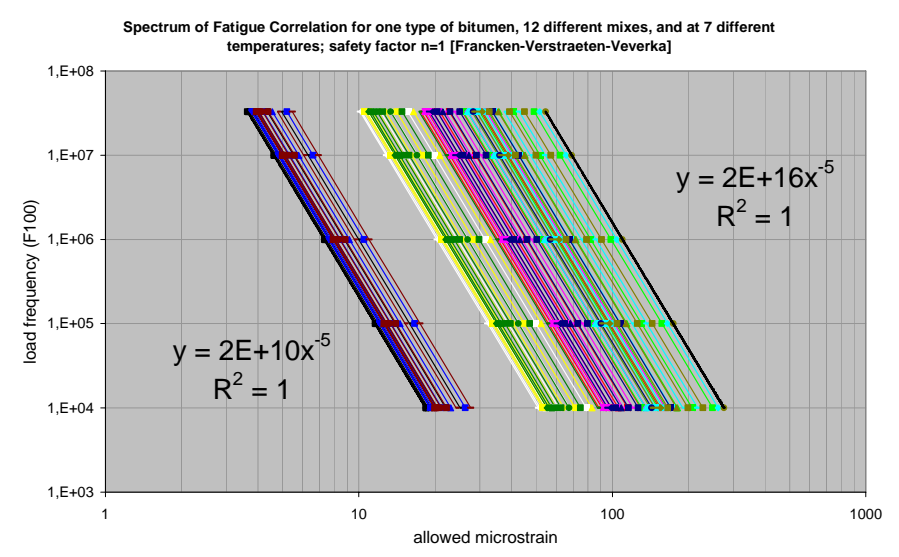

Fig. 5. The spectrum of the fatigue equations

The value of $k_{1}$ coefficient interpreted by Eq. 11 varies together with the modification of temperature, while the type of bitumen and the load period remains unchanged. The values of the exponent of the calculated $k_{1}$ coefficient were calculated for every mix, the values of the exponent were analysed in the function of temperature during which functional relationship was ascertained with tight correlation. The correlation was satisfied by a $5^{\text {th }}$ degree polynomial at the value of $R^{2}>0,9$. Fig. 6 demonstrates the Francken-Verstraeten-Veverka correlation with single, 5-ply and 10-ply angular coefficient, where the change according to the American FHWA correlation was also demonstrated [5, 7, 13].

\subsection{Variation of the fatigue curve according to the type of load}

Applying the surveys of Raithby and Sterling as well as Bonnaure and Co. a parabolic functional correlation was assumed for the temperature range of $+5^{\circ} \mathrm{C}$ and $+45^{\circ} \mathrm{C}$. The change of $f_{3}$ parameter is demonstrated by Fig. 7 based on the results of the

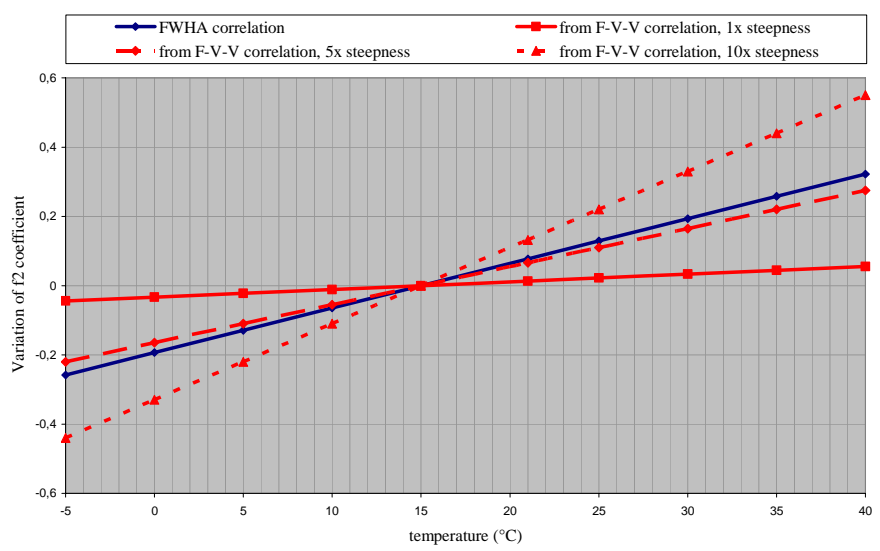

Fig. 6. Variation of $f_{2}$ coefficient in the function of temperature

referred studies [4, 12].

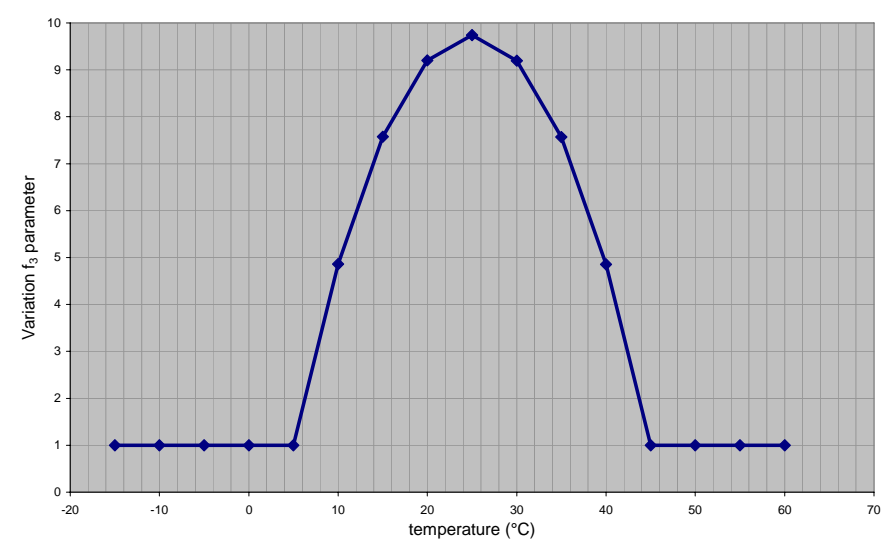

Fig. 7. Variation of $f_{3}$ coefficient in the function of temperature

\subsection{Load cycle number; traffic}

Actual traffic data are required for defining cumulated fatigue values because the behaviour of the pavement structure is influenced fundamentally by the distribution of the traffic.

Magyar Közút Kht. made the traffic (actually measured - not multiplied) survey results available for us referring to the following measurement points: 
- Motorway M1;

- Secondary road No. 117, heavy traffic;

- Primary road No 1, light traffic;

according to which the number of standard axle $(\mathrm{ESAL}=100$ $\mathrm{kN}$ ) were defined. During the implementation of our calculations the calculated temperature figures, the pavement structure models and the stresses generated in the pavement structure, calculated on the basis of the above mentioned points as well as the traffic loads were arranged according to their dates.

\section{Practical application of the cumulated fatigue hy- pothesis}

During the design of the pavement structure, basically the stresses generated by the loading forces are compared to the allowed stresses. On the basis of the hypothesis of cumulated fatigue, the totalling of the allowed cycle numbers for all load cases belonging to the actual and same moment at a given moment must be less than 1 . If the sum of individual partial fatigues reaches 1 , deterioration shall take place. During our calculations we calculated with various pavement structure models according to point 3.1 . We defined 20 pavement structure models in 24 hours, thus the set up of 7300 pavement structure models were made possible for 365 days for the test of one structure.

\subsection{Definition of partial fatigue values}

The calculations were made according to the algorithm demonstrated in Fig. 1 with the help of a specially developed program. The program takes the calculated strains, the temperatures and the traffic as basic data and calculates the allowed cycle number as internal cycle on the basis of the fatigue curve, where the $f_{1}, f_{2}, f_{3}, f_{4}$ parameters of the curve have optionally variable settings. The program calculates the partial fatigue value associated with all the 7300 pavement structures for running the program with parameters $f_{1}-f_{4}$, which is totalled as one figure, then defines the values of the cumulated fatigue curve changing from point to point in the function of the sequence number of the pavement structure, then shows the values in a diagram.

\subsection{Definition of the realistic range of the fatigue straight- line}

Calculating the cumulated fatigues defined on the basis of detailed pavement structures it is possible to find realistic fatigue straight-lines, which were selected on the basis of the long-term observation of pavement structures instead of matching reality to the laboratory tests by selecting shift factors.

In accordance, our starting point was the assumption of two design periods for the pavement structures associated with the individual traffic load classes:

- the pavement structures deteriorate during planning period, and
- assuming a more optimal case the pavement structures deteriorate within 2.5-times the planning period in traffic load category "K", or 2-times the planning period in a lower traffic load category.

Consequently the value of the maximum fatigue assigned to individual years or cumulative fatigue projected for a year can be defined with simple division. According to a sensitivity test performed with the application of various parameters we received the following values:

- in case of asphalt pavement structures $f_{1}=18, f_{4}=-4,6$;

- in case of pavement structures with lean concrete subbase $f_{1}=17 ; f_{4}=-4,7$, which are used for further calculations.

With the application of the defined $f_{1}$ and $f_{4}$ parameters we conducted further sensitivity tests on the pavement structure models. During the sensitivity tests we applied "normal" parameters (defined as described above) for $f_{1}$ and $f_{4}$ parameters, and we applied parameters of very strict fatigue behaviours for the values of $f_{1}$ and $f_{4}$. The latter ones were considered "extreme" parameters, and though these values are physically not possible according to the demonstrated algorithm, we made our calculations with these values as well due to the sensitivity test of the variables.

The $f_{2}$ values were calculated with values of 1,5 and 10-times according to the correlation of Francken-VerstraetenVeverka, parameter $f_{3}$ was associated with the fatigue characteristics or its effect was disregarded. We completed our calculation in every combination of $f_{1}, f_{2}, f_{3}$ and $f_{4}$ as shown in Table 4.

\subsection{Analysis of the cumulated fatigue curve}

The auxiliary program calculates the partial fatigue values of all the 7300 pavement structures during the run of the program for the individual pavement structures, and defines the values of the cumulated fatigue curve changing from point to point in the function of the sequence number of the pavement structure, then shows the value in a diagram.

Our tests found that a five-degree polynomial function can be attached to the points of the cumulated fatigue curve defined in this manner of which the regression coefficient implies reliable functional correlation even in case the fatigue values cumulated to 365 days exceed the value of 1 (physically incapable of interpretation) in large measure. The regression coefficient of the attached polynomial function is always $R^{2}>0.9$, therefore cumulative fatigue is interpreted as a functional correlation in the function of time. The function provided a curve of peculiar behaviour: with strongly increasing sections in the summer months and section with lighter slope in autumn, winter and spring. For the delimitation of the horizontal sections of the fivedegree polynomial we calculated the first differential quotient of the function in every case and searched at which independent variable value it takes up a value less than $\varepsilon$, where $\varepsilon \approx 0$. We 


\begin{tabular}{|c|c|c|c|c|c|c|c|}
\hline \multicolumn{8}{|c|}{ full depth asphalt pavement structure with traffic load categories C, D, E and K } \\
\hline \multirow{4}{*}{$\begin{array}{c}\text { normal } \\
\text { parameters }\end{array}$} & $\mathrm{f} 1$ & 18 & 18 & 18 & 18 & 18 & 18 \\
\hline & f2 & $1 \mathrm{x}$ & $1 \mathrm{x}$ & $5 x$ & $5 x$ & $10 x$ & $10 x$ \\
\hline & f3 & has effect & no effect & has effect & no effect & has effect & no effect \\
\hline & $\mathrm{f} 4$ & -4.6 & -4.6 & -4.6 & -4.6 & -4.6 & -4.6 \\
\hline \multirow{4}{*}{$\begin{array}{c}\text { extreme } \\
\text { parameters }\end{array}$} & f1 & 17 & 17 & 17 & 17 & 17 & 17 \\
\hline & f2 & $1 \mathrm{x}$ & $1 \mathrm{x}$ & $5 x$ & $5 x$ & $10 x$ & $10 x$ \\
\hline & f3 & has efect & no effect & has effect & no effect & has effect & no effect \\
\hline & $\mathrm{f} 4$ & -5.4 & -5.4 & -5.4 & -5.4 & -5.4 & -5.4 \\
\hline \multirow{4}{*}{$\begin{array}{c}\text { normal } \\
\text { parameters }\end{array}$} & f1 & 17 & 17 & 17 & 17 & 17 & 17 \\
\hline & f2 & $1 x$ & $1 x$ & $5 x$ & $5 x$ & $10 x$ & $10 x$ \\
\hline & f3 & has effect & no effect & has effect & no effect & has effect & no effect \\
\hline & $\mathrm{f} 4$ & -4.7 & -4.7 & -4.7 & -4.7 & -4.7 & -4.7 \\
\hline \multirow{4}{*}{$\begin{array}{c}\text { extreme } \\
\text { parameters }\end{array}$} & f1 & 16 & 16 & 16 & 16 & 16 & 16 \\
\hline & f2 & $1 x$ & $1 x$ & $5 x$ & $5 x$ & $10 x$ & $10 x$ \\
\hline & f3 & has efect & no effect & has effect & no effect & has effect & no effect \\
\hline & $\mathrm{f} 4$ & -5.4 & -5.4 & -5.4 & -5.4 & -5.4 & -5.4 \\
\hline
\end{tabular}

found that the cumulated fatigue value calculated for each pavement structure and the product of a c constant provides a sufficient $\varepsilon$ value, so during our test:

$$
\frac{d y}{d x}<c \sum_{i=1}^{n} n_{i}
$$

where

$y$ is the polynomial function set to the cumulated fatigue;

$x \quad$ sequential number of the pavement structures (time indirectly);

$c \quad$ constant, $\mathrm{c}=2 \mathrm{E}-5$;

$n_{i} \quad$ fatigue values of a section according to the hypothesis of Miner.

The nature of the cumulated fatigue curve is showed on Fig. 8 in the environment of transition from months with different air temperatures.

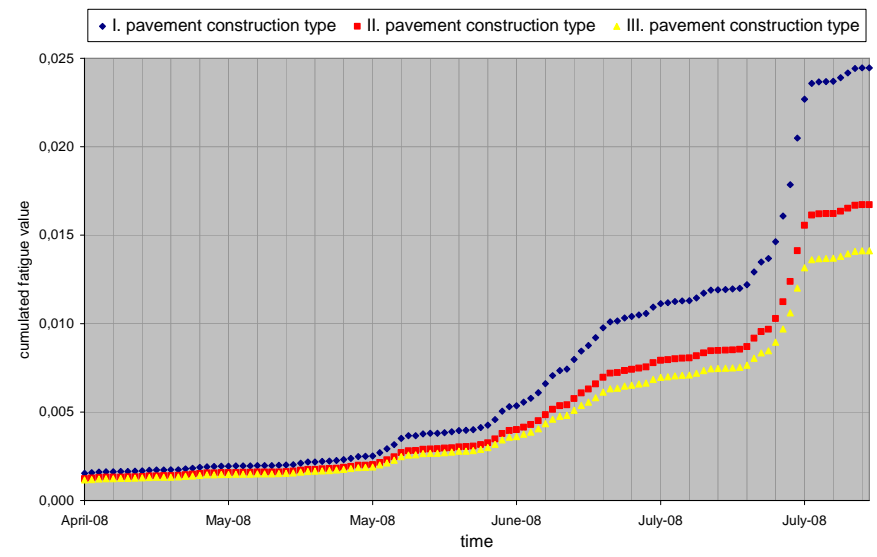

Fig. 8. Nature of the cumulated fatigue curve, full depth asphalt pavement construction, traffic load class $\mathrm{K}$

With the help of the program we collected the independent variable values for every type of pavement structure where the correlation defined by Eq. 3 is valid. According to Fig. 9 a period can be defined for all the pavement structures and selecting the outermost time value as definitive, within that it is true for all the pavement structures that the partial fatigues defined by the pavement structure models set up for the given period and according to the fatigue characteristics calculated with the consideration of the temperatures of the associated pavement structures are specifically higher than the values outside the referring period. By that the period falling between 1 April and 1 October, definitive in terms of fatigue can be delimited.

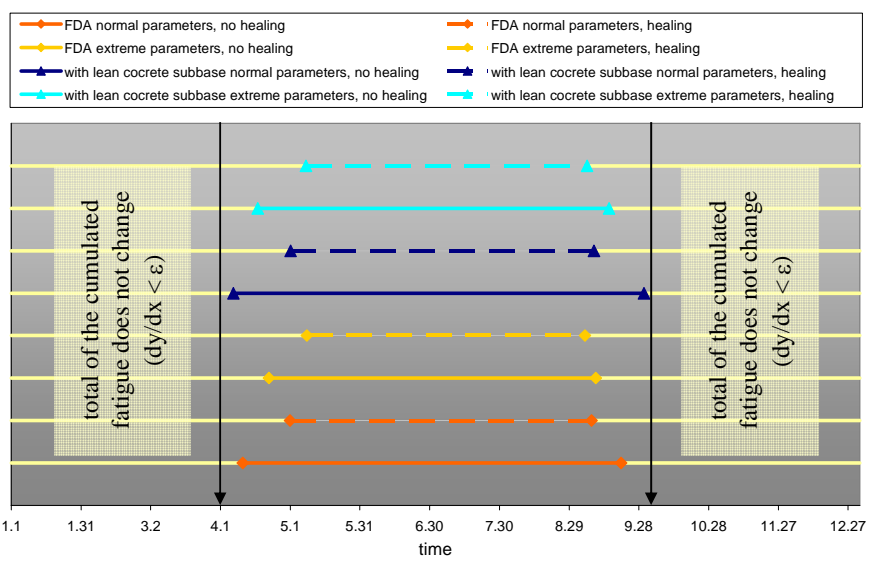

Fig. 9. Limits of the changes of cumulated fatigue within a calendar year

Taking the healing effect into consideration the definitive period is rather restricted to the summer months; the late spring and early autumn period will not be definitive and the variance calculated from the results of various pavement structures will also be reduced. The real extent of the influence of healing effect can be approximated with the help of refining the models set up for defining the extent of influence. 
Tab. 5. Calculated values of the limits of the cumulated fatigue

\begin{tabular}{ccccc}
\hline & \multicolumn{4}{c}{ averaged according to the value of f2 } \\
\cline { 2 - 5 } average and scattering value & \multicolumn{3}{c}{ no healing } & there is healing \\
\cline { 2 - 5 } & start & end & start & end \\
\hline \multicolumn{5}{c}{ full depth asphalt pavement construction with normal parameters } \\
\hline average & 20 September & 10 April & 7 September & 30 April \\
standard deviation (day) & 7.6 & 5.6 & 1.9 & 4.1 \\
\hline full depth asphalt pavement construction with extreme parameters \\
\hline average & 9 September & 21 April & 4 September c8 May \\
standard deviation (day) & 2.6 & 4.3 & 0.7 & 2.7 \\
\hline lean concrete subbase asphalt pavement construction with normal parameters \\
\hline average & 30 September & 6 April & 8 September & 1 May \\
standard deviation (day) & 11.6 & 6.4 & 2.3 & 4.5 \\
\hline lean concrete subbase asphalt pavement construction with extreme parameters \\
\hline average & 15 September & 17 April & 5 September & 7 May \\
standard deviation (day) & 5.4 & 5.1 & 1.1 & 3.0 \\
\hline
\end{tabular}

\section{Conclusions}

During our calculations of demonstrating the importance of continuous change of temperature in the pavement structure we used the results of measurements that were actually performed. During the calculations we used the temperature measurement results of an entire year and the dynamic modules of the asphalt mix defined on the basis of laboratory tests for setting up detailed pavement structure models.

According to the detailed model calculations we delimited the seasons characterizing respecting load capacity fatigue. Taking the results of the demonstrated calculations into account some considerations seem useful for the practical design of the pavement structure.

With the application of asphalt and using the design experiences of the past decades long lasting pavement structures can be built, but special care must be stowed on the design criteria projecting the future performance of the pavement structure. Its importance was shown at the delimitation of the range of fatigue curves as well.

From the behaviour of the cumulative fatigue curve it is obvious that the cumulative fatigue value rises steeply due to extremely high temperature values, so these considerations are viable in terms of operation as well. Such applications may be city motorways and lane construction of intersections. Fig. 10 demonstrates a summer day, where the partial fatigue values are also showed in the function of time (non-cumulative), together with the surface modulus of the pavement structure. It can be demonstrated easily that the individual partial fatigue values increase significantly in the afternoon in comparison with the values measured during dawn. The distribution of the partial fatigue values obviously depends on traffic, consequently in case of pavement structures where the rush hour load takes place in the afternoon or early evening hours the pavement structure must be built taking that information into account, or temperature re- duction must be solved as part of the maintenance (e.g. regular spraying, light colour cover, etc.)

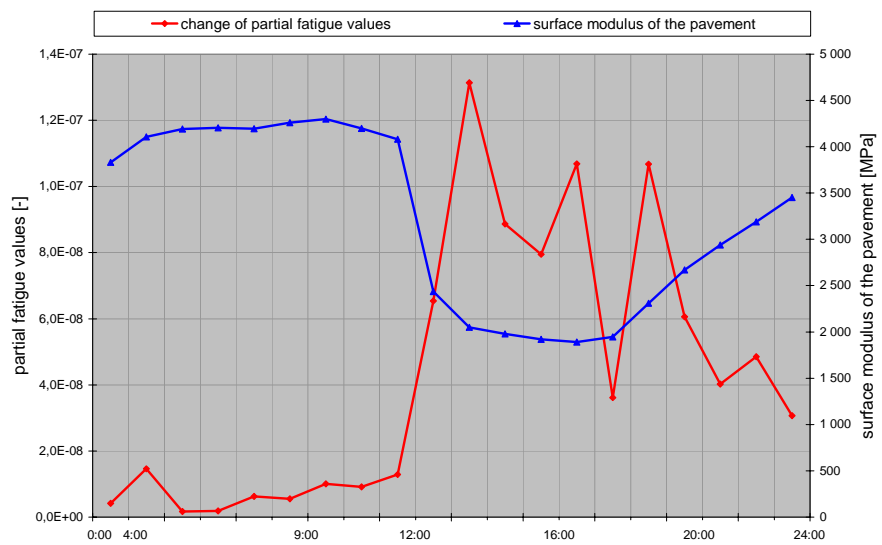

Fig. 10. Variation of the pavement structure in the function of time and temperature in accordance

The calculations can provide input for designing the mix or selecting the layer structures, as example high modulus asphalt (HMA) must be mentioned. As we could see high temperature enhances not only the formation of rutting but also the bearing capacity of the pavement structure. Utilization of HMA for the full load-bearing layer may be a realistic concept depending upon the design concept; the excellent fatigue resistance feature of the high modulus asphalts also justifies their use thanks to the comparatively high binder content (5.9-6.3 m\%). Depending on the design concept (considering its extra costs as well) its seems advisable that high modulus asphalts should be built into the base course only if it is enabled by the various limit conditions of asphalt technology as well. 


\section{References}

1 Arand W, Lorenzl H, Einfluß der Bitumenhärte auf das Ermüdungsverhalten von Asphaltbefestigungen unterschiedlicher Dicke in Abhängigkeit von der Tragfähigkeit der Unterlage der Verkehrsbelastung und der Temperatur 969 (1994). Teli 2, F.S.u.S.

2 Claessen AIM, Edwards JM, Sommer P, Ugé P, Asphalt Pavement Design, The Shell Method,4th Int.Conf. on Des. of Asph. Pav., 1977, pp. 39-65.

3 De Jong DL, Peutz MGF, Korswagen AR, Computer Program BISAR. Layered Systems under Normal and Tangential Surface Loads., Koninklijke/Shell Laboratorium, Amsterdam, 1973. External Report AMSR.0006.73.

4 Bonnaure FP, Huibers AHJJ, Boonders A, A Laboratory Investigation, of the Influence of Rest Periods on The Fatigue Characteristics of Bituminous Mixes, AAPT 51 (1982), 104-128.

5 FHWA :Sensitivity Analysis of FHWA Structural Model VESYS II.: Preparatory and Related Studies, Vol. 1, Federal Highway Administration, Washington D.C., 1976. Report No. FHWA-RD-76-23.

6 Huang YH, Pavement Analysis and Design, University of Kentucky, 2004.

7 Kingham RI, Failure criteria developed from AASHO road test data, Proc. of the 3rd Int. Conf. on the Str. Des. of Asph. Pav., 1972, pp. 656-669.

8 Miner MA, Cumulative Damage in Fatigue, The American Society of Mechanical Engineers 67 (1945), 159-164.

9 Myre J, Fatigue of Asphalt Materials for Norwegian Conditions, Proc. of the 7th Int. Conf. on the Str. Des. of Asph. Pav., 1992, pp. 238-251.

10 Nemesdy E, The new Hungarian pavement structure design concept, Közlekedésépítés- és Mélyépítés-tudományi Szemle 42 (1992), no. 8 (Hungarian).

11 Palmgreen A, Die Lebensdauer von Kugallagern, Zeitschrift des Vereines Deutscher Ingenieure 68 (1924), 339-341.

12 Raithby KD, Sterling AB, Laboratory Fatigue Tests on Rolled Asphalt and their Relation to Traffic Loading, Roads and road construction 50 (1972), 219-223.

13 Verstraeten J, Romain JE, Veverka V, The Belgian Road Research Center's Overall Approach to Asphalt Pavement Structural Design (1977). Authorized Reprint from Copyrighted Volume 1 Proceedings The University of Michigan.

14 Wöhler E, Resultate der in der Central-Werkstatt der NiederschlesichMärkischen Eisenbahn zu Frankfurt a.d.O. angestellten Versuche über die relative Festigkeit von Eisen: Stahl und Kupfer, Zeitschrift für Bauwesen XVI (1866), 67-84. 